\title{
Lotus, quantos despropósitos são proferidos em teu nome! Considerações sobre o conceito de soberania na jurisprudência da Corte Mundial ${ }^{1}$
}

\author{
Alain Pellet ${ }^{2}$ \\ Professor na Universidade Paris X-Nanterre, membro e antigo Presidente da C. D. I. E-mail: \\ courriel@alainpellet.eu \\ Tradução de Eraldo Silva Júnior \\ Mestre e doutorando em Direito Internacional na Universidade do Estado do Rio de Janeiro \\ (UERJ). Defensor Público Federal. E-mail: eraldo.silva@dpu.def.br
}

\begin{abstract}
Resumo
O caso Lotus, julgado pela Corte Permanente de Justiça Internacional em 1927, é, até a presente data, o precedente mais notável quanto à delimitação da soberania estatal no plano internacional. Apesar de a redação do julgado parecer apontar de modo incontestável para uma concepção absoluta da soberania, sua adequada interpretação é objeto de longos debates ao longo do último século. Neste artigo, a decisão da CPJI é analisada a fundo, visando determinar se, de fato, esta pende a uma concepção absoluta de soberania.

Palavras-chave

Direito Internacional Público; Corte Permanente de Justiça Internacional; Corte Internacional de Justiça; Soberania; Limitações à Soberania Estatal.
\end{abstract}

\footnotetext{
${ }^{1}$ Originalmente publicado com o título Lotus, que de sottises on profêre en ton nom!: remarques sur le concept de souveraineté dans la jurisprudence de la Cour mondiale, na obra Mélanges en l'honneur de Jean-Pierre Puissochet: l'État souverain dans le monde d'aujourd'hui, Paris, 2002, pp. 215-230.

${ }^{2}$ Agradeço fortemente a Céline Folsché, doutoranda na Universidade Robert Schuman, Estrasburgo, LL.M em International Legal Studies, New York University, que se debruçou com ardor sobre as "pesquisas lotusianas" na ocasião de seu estágio durante a sessão da Comissão de Direito Internacional (2007).
}

Revista Publicum

Rio de Janeiro, v. 3, n. 1, 2017, p. 60-77

http://www.e-publicacoes.uerj.br/index.php/publicum

DOI: 10.12957/publicum.2017.30214 


\section{Sumário}

I. Uma concepção apenas aparentemente "absoluta" da soberania; II. Uma concepção ambígua da soberania justificada pela sequência de posições diferentes e irreconciliáveis.

Mesmo havendo um quê de simplificação acadêmica nesta distinção, que não é evidentemente rígida, os julgados da Corte Mundial podem ser divididos em duas grandes categorias: há os que se fixam estritamente à missão da Corte e resolvem as disputas a ela submetidas com base no direito aplicável nos estritos limites dos fatos do caso, e aqueles nos quais, indo além, a Alta Jurisdição produz obra doutrinária ou mesmo "quase legislativa" ${ }^{3}$. O julgado da CIJ de 3 de fevereiro de 1994 no caso da Disputa Territorial (Líbia/Chade) ${ }^{4}$ constitui, sem dúvidas, o melhor exemplo do primeiro caso, aquele da CPJI de 7 de setembro de 1927 no caso Lotus ${ }^{5}$, o exemplo clássico do segundo ${ }^{6}$. Este último é também um daqueles julgados, talvez o principal, que deu lugar a controvérsias doutrinárias mais vivas.

\footnotetext{
*Artigo originalmente publicado em francês: "Lotus, que de sottises on profère en ton nom! : remarques sur le concept de souveraineté dans la jurisprudence de la Cour mondiale", Mélanges en I'honneur de Jean-Pierre Puissochet : I'État souverain dans le monde d'aujourd'hui, Pedone, Paris, 2008, p. 215-230. Tradução feita para o português por Eraldo Silva Júnior, defensor público federal, mestre em direito internacional pela Universidade do Estado do Rio de Janeiro, doutorando em direito internacional na Universidade do Estado do Rio de Janeiro.

${ }^{* *}$ Agradeço fortemente a Céline Folsché, doutoranda na Universidade Robert Schuman, Estrasburgo, LL.M em International Legal Studies, New York University, que se debruçou com ardor sobre as "pesquisas lotusianas" na ocasião de seu estágio durante a sessão da Comissão de Direito Internacional (2007).

3 V. Alain Pellet, "L'adaptation du droit international aux besoins changeants de la société internationale", Académie de Droit international, conférence inaugurale, 23 juillet 2007, à paraître in R.C.A.D.1. 2007.

${ }^{4}$ Rec. 1994 , p. 6.

${ }^{5}$ Série A, no10, p. 3; também podemos incluir nesta categoria, por exemplo, o julgado da C.U. de 20 de fevereiro de 1969 no caso da Plataforma continental do Mar do Norte, Rec. 1969, p. 3, ou a opinião consultiva de 2 de abril de 1949 relativa à Reparação de danos sofridos em serviço às Nações Unidas, Rec. 1949, p. 174, ou de 28 de maio de 1951 sobre as Reservas à Convenção sobre a prevenção e a repressão ao Genocídio, Rec. 1951, p. 15.

${ }^{6}$ Os comentaristas contemporâneos insistem no fato de que se trata do primeiro caso submetido à Corte versando sobre problemas de direito internacional geral (v. por exemplo: W.E. Beckett, "Criminal Jurisdiction over Foreigners - The Franconia and the Lotus", B.Y.B.1.L. 1927, p. 09; J.L. Brierly, "The 'Lotus' Case", The Law Quarterly Review 1928, p. 154, ou G. Wendel! Berge, "The Case of the S.S. 'Lotus'”, Michigan L. Rev. 1927-1928, p. 361); com o passar do tempo, isso parece deveras discutível: os casos do Vapor Wimbledon ou das Concessões Mavrommatis exerceram uma influência maior na evolução do direito internacional real e geral.
}

Revista Publicum

Rio de Janeiro, v. 3, n. 1, 2017, p. 60-77

http://www.e-publicacoes.uerj.br/index.php/publicum

DOI: 10.12957/publicum.2017.30214 
Proferido graças à voz preponderante do Presidente Max Huber7 , a decisão de 1927 se baseia em uma concepção de soberania da qual muitas vezes se exagerou o escopo absoluto (I) e que, em todo caso, se presta a interpretações divergentes, como demonstram as análises que foram feitas posteriormente (II) ${ }^{8}$.

\section{Uma concepção apenas aparentemente "absoulta" da}

\section{soberania}

Como muitas das "grandes decisões", a de 1927 foi proferido versando sobre fatos deveras inofensivos. Trata-se, sem dúvidas, de uma das decisões na qual o caso concreto é dos mais insignificantes ${ }^{9}$ dentre todos submetidos à Corte: uma colisão ocorrida em alto-mar entre o barco a vapor francês Lotus e o navio turco Boz-Court, resultando na morte de oito marinheiros e passageiros turcos; após a chegada do Lotus a Istambul, a Turquia, tendo exercido, "paralelamente à atuação contra o capitão do navio turco, medidas de persecução penal conexas em virtude da legislação turca contra o senhor Demons, Oficial de Quarto a bordo no Lotus no momento da colisão" ${ }^{10}$. Esta pretensão resultou em protestos por parte da França que entendia que "os fatos ocorridos em alto-mar a bordo de um navio comercial não são, a princípio, sujeitos à jurisdição penal de tribunais diversos daqueles do Estado cujo pavilhão o navio porta" ${ }^{11}$.

Para resolver este problema, a Corte poderia ter se limitado ao exame das regras técnicas aplicáveis ${ }^{12}$. Provavelmente sob impulso de Anzilotti ${ }^{13}$, ela fez um desvio

\footnotetext{
${ }^{7}$ A opinião dissidente do Juiz Americano J.B. Moore concorreu neste ponto com a da maioria no que concerne à inexistência de uma regra de direito internacional reservando a competência penal em casos de colisão em alto-mar ao Estado da bandeira (série A, no10, pp.65-94, em especial p.65).

${ }^{8} \mathrm{~A}$ literatura destinada ao Lotus é extremamente abundante; o presente estudo se limitará ao estudo das opiniões pessoais dos Juízes da Corte mundial. Quanto à Corte propriamente dita, ela, de modo geral, se absteve prudentemente de fazer referência aos supostos "princípios de Lotus".

${ }^{9}$ Esta "insignificância" não se relaciona evidentemente às perdas humanas resultantes da colisão (que não foram causa da ação, salvo se muito indiretamente), mas ao objeto da disputa, que versava sobre os quarenta dias de prisão e uma multa moderada impostas ao Oficial de Quarto francês pelos tribunais turcos.

${ }^{10}$ Compromisso de 12 de outubro de 1926, artigo 1ㅇ, ponto (1), reproduzido no julgado, p. 5 e na CPJI, série $X$, no13/2, p.25.

${ }^{11}$ Conclusões dos memoriais franceses reproduzidas à página 7 do julgado.

12 Ela o fez em toda a segunda metade do julgado e chegou à sua conclusão com base em argumentos discutíveis ou, atualmente, de todo modo obsoletos, como a velha tese da "territorialidade" dos navios. (v. p. 23 ou p. 25 - v. irifra, note 27 et p. [7]). En ce sens: A.P. Fachiri, "The Case of the Lotus", B. YB.LL. 1928, pp. 131-134.

${ }^{13}$ Sabe-se que ele redigiu a parte principal do julgado (cf. Max Huber, "Tagbuch",18 de agosto 1927, apud Ole Spiermann, International Legal Argument in the Permanent Court of International Justice The Rise of the International Judiciary, Cambridge V.P., 2005
}

Revista Publicum

Rio de Janeiro, v. 3, n. 1, 2017, p. 60-77

http://www.e-publicacoes.uerj.br/index.php/publicum

DOI: 10.12957/publicum.2017.30214 
doutrinário considerável que lhe permitiu explicitar, em um parágrafo que fez muita tinta ser gasta posteriormente, sua concepção quase caricaturalmente positivista de soberania:

\begin{abstract}
O direito internacional rege as relações entre Estados independentes. As regras de direito ligando os Estados se originam, assim, da vontade destes, vontade esta manifesta nas convenções ou nos costumes geralmente aceitos como consagradores dos princípios de direito e estabelecidos visando reger a coexistência dessas comunidades independentes ou visando a busca de objetivos comuns. As limitações à independência dos Estados não podem, portanto, serem presumidas ${ }^{14}$.
\end{abstract}

Essas três frases, que são um prato cheio para os autores que reclamam do positivismo voluntarista, são inegavelmente criticáveis e, ademais, não têm o escopo rigidamente "soberanista" que lhe foi atribuído.

Parece dificilmente contestável que "[a]s limitações à independência dos Estados não podem (...) ser presumidas" ${ }^{\prime \prime}$, salvo para esvaziar todo o escopo do próprio conceito de independência-soberania ${ }^{16}$. Ainda, deve-se ter uma visão razoável de tal conceito, compatível com a própria existência de uma sociedade internacional tal qual podemos observar, e à qual se aplica um direito digno de tal nome. Ora, de um lado, a sociedade internacional contemporânea à qual se aplica o direito internacional não é constituída somente de Estados independentes (mesmo se, sem ofensa a alguns, eles ainda sejam o componente principal)e, de outro, não é preciso afirmar que as regras de direito ligando os Estados procedem exclusivamente da vontade destes (mesmo se uma parte consideravelmente preponderante de tais normas de fato tenha esta origem).

Além disso, não é isto que diz a Corte permanente: ela certamente considera que o direito internacional rege as relações entre os Estados - mas ela não limita seu domínio a essas $^{17}$; e ela indica que as regras de direito internacional se originam da vontade dos Estados, não afirma ser esta a única origem possível. É, contudo, neste ponto que suas afirmações são mais criticáveis, pois, na falta de advérbio, recorre ao artigo "as" ("As regras de direito

${ }^{14}$ CPJI, série $A, n=10$, p.18.

15 Não deixa de ser interessante notar que Anzilotti e Max Huber - muito provavelmente os dois principais inspiradores do julgado Lotus, tenham utilizado uma fórmula muito próxima na opinião dissidente comum que apresentaram no julgamento da Corte permanente de 17 de agosto de 1923 no caso do Vapor Wimbledon (série $A, n=1, p .37$ ).

16 De acordo com a célebre fórmula de Max Huber (que presidia a CPJI em 1927 e cuja voz preponderante foi essencial para a construção da decisão): "[a] soberania nas relações entre Estados significa independência" (C.P.A., sentença arbitral de 4 de abril de 1928, caso da Ilha das Palmas, R.S.A., vol. II, p.838; veja também a sentença de Max Huber de 1ㅇ de maio de 1925 no caso dos Bens britânicos no Marrocos espanhol. R.S.A.N.U. II, p.642).

${ }^{17}$ Isso se aplica mesmo quando, um pouco mais tarde no julgamento, "a Corte considera que o sentido dos termos 'princípios de direito internacional' não pode, de acordo com seu uso corriqueiro, significar outra coisa que não o direito internacional tal qual esteja este em vigor entre todas as nações integrantes da comunidade internacional" (pp.16-17).

Revista Publicum

Rio de Janeiro, v. 3, n. 1, 2017, p. 60-77

http://www.e-publicacoes.uerj.br/index.php/publicum

DOI: 10.12957/publicum.2017.30214 
ligando os Estados...”) o que poderia fazer pensar que não há outra alternativa. A palavra "portanto" inclusa na terceira frase, reforça esta impressão: parece implicar que, por reger a relação entre Estados soberanos, o direito internacional somente pode ser fundado em sua vontade $^{18}$. É nessa brecha lamentável que a doutrina positivista mergulhou triunfantemente.

O recorte inevitavelmente limitado da presente contribuição não permite que nos debrucemos sobre quão reducionista e artificial é esta visão. E, mesmo tendo o homenageado por estas linhas há muito tenha desgastado o discurso do Quai d'Orsay ${ }^{19}$, frequentemente tentado por um positivismo com ênfase no nacionalismo jurídico, estou convencido de que, em comparação com as realidades da vida internacional ou comunitária, não se pode deixar de constatar que entre o "eu quero" e o "eu posso" (no direito e na realidade) há algo que somente uma doutrina demasiadamente cravada de certezas soberanistas pode negar.

Basta dizer - mas estes são apenas os argumentos mais evidentes que vão de encontro a uma abordagem exclusivamente voluntarista do rule of law $w^{20}$ - que esta:

- explica (superficialmente) o fundamento das regras convencionais, mas não a razão pela qual os tratados constituem "grilhões à vontade", dos quais as Partes não podem se libertar unilateralmente uma vez que tenham entrado em vigor;

- não permite justificar o caráter obrigatório das regras costumeiras em relação aos Estados que não participaram de sua formação (e explica de modo muito artificial para aqueles que participaram reduzindo a opinio juris a um "acordo tácito"), nem o dos princípios gerais de direito, cuja obrigatoriedade no plano internacional nada deve, de fato, à vontade dos Estados;

- não pode ser conciliada com a existência de normas imperativas de direito internacional geral que se impõem aos Estados mesmo contra sua vontade e que eles não podem afastar através de um tratado em sentido diverso;

- não leva em consideração as condições reais da formação de regras jurídicas internacionais, que resultam de um processo; e

18 Para uma posição com mais nuances (e mais precisa), v. a opinião dissidente de Loder segundo a qual o direito internacional "baseia-se em conviç̧ões gerais" cujas "regras podem ser modificadas, alteradas, desenvolvidas seguindo a visão de uma maioria considerável desses Estados, de acordo com a evolução dessas conviç̧ões gerais" (p.34).

19 NT : referência feita à Assembleia Nacional Francesa, situada no Quai d'Orsay, em Paris.

20 Para uma crítica mais sistemática, v. A. Pellet, "Le bon droit et l'ivraie - Plaidoyer pour l'ivraie (Remarques sur quelques problèmes de méthode en droit intemational)", Mélanges Charles Chaumont, Pedone, Paris, 1984, pp. 465-493; "Contre la tyrannie de la ligne droite - Aspects de la formation des normes en droit international de l'économie et du développement", in Thesaurus Acroasium (Thessalonique), vol. XIX, 1992, pp. 287-355; ou "Cours général: le droit international entre souveraineté et communauté internationale - La formation du droit international", Anuário Brasileiro de Direito Internacional, vol. II, 2007, pp. 12-74.

Revista Publicum

Rio de Janeiro, v. 3, n. 1, 2017, p. 60-77

http://www.e-publicacoes.uerj.br/index.php/publicum

DOI: 10.12957/publicum.2017.30214 
- traduz uma abordagem tristemente cínica do direito internacional, exalando uma soberania cuja concepção absoluta deu lugar no passado - e continua a dar lugar- aos abusos mais graves.

Esta concepção pode encontrar algum amparo numa leitura literal da decisão proferida pela CPJI no caso Lotus. Mas ela não é obrigatória e outras interpretações são possíveis. Como escreveu Sir Hersch Lauterpacht, “em uma análise mais detalhada, (...) o princípio enunciado pela Corte é menos dogmático e mais flexível do que uma primeira leitura faz parecer" $^{\text {"21 }}$. O ilustre autor entende que, na passagem já citada, a Alta Jurisdição fez referência à vontade ${ }^{22}$ dos Estados “como exteriorizada não apenas pelas convenções, mas também 'pelos costumes geralmente aceitos'. Um 'costume geralmente aceito' é aquele aceito pela generalidade dos Estados, não necessariamente por todos os Estados "23.

De qualquer forma, não se pode encontrar no julgado de 1927 o enunciado de uma regra geral e absoluta de liberdade. Mesmo se admitirmos que dele resulta que "tudo que não é proibido é permitido" - o que o julgado não enuncia desta forma ${ }^{24}$-, este princípio valeria apenas para as atividades conduzidas pelo Estado dentro de seu próprio território ${ }^{25}$. Embora isto não seja determinado na passagem citada anteriormente, o parágrafo que a segue imediatamente não deixa dúvidas:

Ora, a limitação primordial que o direito internacional impõe ao Estado é a de excluir - ressalvada a existência de regra permissiva em sentido oposto - todo exercício de seu poder sobre o território de um outro Estado. Nesse sentido, a jurisdição é certamente territorial; ela não pode ser exercida fora do território, salvo em virtude de uma regra permissiva decorrente do direito internacional costumeiro ou de uma convenção ${ }^{26}$.

Waldock, que se monstra infinitamente menos crítico que Lauterpacht em relação à decisão de 1927, concorda, de resto, que a questão era saber se a Turquia "podia exercer sua jurisdição territorial, a não ser que a França pudesse apontar uma regra que restringisse dito exercício...",27.

${ }^{21}$ The Devolpment of International Law by the International Court, Stevens, London, 1958, p. 360.

22 "Free will" no texto em inglês.

${ }^{23}$ Op. cit. note 17, p. 360 ; no mesmo sentido: Maurice Travers, “L'affaire du 'Lotus'”, R.D.J.L. C. 1928, pp. 405-406 et p. 415.

${ }^{24}$ Como foi escrito, "literalmente, o Lotus não deu origem à presunção de liberdade: ele rejeitou uma presunção contra a liberdade" (O. Spiermann, op. cit. note II, p. 254).

${ }^{25}$ Nesse sentido, v. Sir Gerald Fitzmaurice, The Law and Procedure of the International Court of Justice, Grotius Publics., vol. 1, 1986, p. 147.

${ }^{26}$ Série A, $n^{\circ} 10$, pp. 18-19 - itálicos adicionados.

27 "General Course on Public International Law", R.C.A.D.I. 1962-11, vol. 106, p. 165 - itálicos adicionados. 
Isto não faz nada além de confirmar que as competências de um Estado sobre seu próprio território são particularmente amplas e não cedem salvo se perante uma regra expressa que as limitem, isto que traduz a expressão "soberania territorial"; como escreveu Weiss em sua opinião dissidente - porém, neste ponto, compatível com a opinião da Corte ${ }^{28}$ , o que estava em discussão, “[é] em primeiro lugar, o princípio da soberania dos Estados em matéria repressiva, e não o da soberania universal, indefinida, ilimitada, da qual a Turquia entendia gozar, mas da soberania que tem seu fundamento e seu limite no território sobre o qual o Estado exerce sua autoridade, isto é, a soberania territorial "29. Os outros juízes dissidentes não arrazoaram de forma diferente ${ }^{30}$. Porém, de forma oposta, não seria assim fora do território do Estado: não existe "soberania pessoal" ou "extraterritorial".

O posicionamento de Max Huber (que presidia a Corte permanente em 1927 e cuja voz preponderante permitiu a adoção a decisão) é interessante sob este aspecto. Em suas observações de 1931 sobre o relatório de Louis Le Fur ao Instituto de Direito Internacional sobre a determinação, pelo direito internacional, do domínio deixado à competência exclusiva de cada Estado, escreveu continuar "a pensar que o princípio proclamado pela Corte permanente de Justiça internacional no caso 'Lotus' é correto, mas”, adiciona, "foi de certa forma mal interpretado pelos críticos de tal decisão. A ausência de uma regra que divida os direitos entre os Estados e a liberdade que dela resulta de cada Estado em fazer o que não é proibido não significa um estado de anarquia no qual cada um teria o direito de ignorar a situação criada por um outro Estado. Lá, onde as liberdades produzem uma colisão real, o direito deve fornecer a solução, porque o direito internacional, como todo direito, repousa sobre a ideia de coexistência de vontades de igual valor" ${ }^{31}$.

${ }^{28}$ Por sua vez, a Corte afirmou que: "a territorialidade do direito penal não é, assim, um princípio absoluto do direito internacional e tampouco se confunde de forma alguma com a soberania territorial." (Série A, $n^{\circ} 10$, p. 20), ela se limita "a revelar que, na espécie, as persecuções penais podem ser justificadas também em vista ao princípio dito da territorialidade" (p.23).

29 Ibid., p.49 - itálicos adicionados.

${ }^{30}$ V. J.B. Moore: "[é] um princípio reconhecido de direito internacional que um Estado possui e exerce, em seu próprio território, uma jurisdição absoluta e exclusive, e que toda exceção a este direito deve se originar do consentimento do Estado, seja expresso, seja implícito (Schooner Exchange cl McFaddon, 1812 - 7 Cranch 116, 136)" (Série A, nO 10, p. 67 - itálicos adicionados); como a "maioria" (ibid., p.25), o Juiz americano admite com firmeza que "[é] universalmente admitido que um navio em alto-mar deve, sob o ponto de vista da competência judicial, ser considerado como parte do território do país do qual ele partiu" (p.68), o que não seria aceitável atualmente (v. de qualquer forma a opinião dissidente de Lord Finlay, p. 53); v. também Nyholm, ibid., p.59 ou Altamira, que admite, contudo, exceções "nos casos extremos e absolutamente necessários ou inevitáveis" (p.95). Lord Finlay se coloca no território mais limitado da proteção dos nacionais no exterior e considera que "[t]odo Estado que julgue necessário adquirir este poder deveria, por convenção, garantir o consentimento dos outros Estados afetados" (p.56).

${ }^{31}$ Ann. I.D.I., Session de Cambridge 1931, vol. 1, p. 79 - itálicos no texto; v. também a esse respeito: Ole Spiermann, "Judge Max Huber at the Permanent Court of International Justice", E.J.I.L. pp. 129-

Revista Publicum

Rio de Janeiro, v. 3, n. 1, 2017, p. 60-77

http://www.e-publicacoes.uerj.br/index.php/publicum

DOI: 10.12957/publicum.2017.30214 
O problema foi colocado de modo admirável pelo Juiz Shahabuddeen em sua opinião dissidente apresentada na opinião consultiva da Corte no caso da Licitude da ameaça ou do emprego de arma nuclear:

\begin{abstract}
Nenhum argumento convincente permite sustentar que, no caso da Lotus, a Corte teria aderido à ideia de que os Estados possuem uma soberania absoluta, os habilitando a empreender qualquer ação, não importando quão horrível e detestável pudesse essa parecer aos olhos da comunidade internacional, desde que não reste provado que tal ação é proibida pelo direito internacional. A ideia da supremacia interna associada à noção de soberania em direito interno não é aplicável como tal quando se transpõe esta noção para o plano internacional. A coexistência de um determinado número de soberanias impõe limites à liberdade de cada Estado agir como se os outros Estados não existissem. Estes limites definem um quadro estrutural objetivo, no qual a soberania deve necessariamente existir; o quadro, bem como os limites que o definem, estão implícitos na referência feita no julgado Lotus à 'coexistência de comunidades independentes' (CPJI série A, $\left.n^{\circ} 10, p .18\right) \ldots{ }^{32}$.
\end{abstract}

Eis o ponto central da questão: a soberania não teria, na esfera internacional, as características de absoluta, incondicional e ilimitada que a ela se pode atribuir na ordem interna. Enquanto, nessa última, seu titular é único - seja o Príncipe, a nação, o povo ou o Estado-, no plano internacional, ela não pertence ao Estado, mas igualmente a todos os Estados. Portanto, cada uma das competências é limitada pelas demais, iguais, pertencentes a todos os outros; e a função principal, fundamental, do direito internacional é organizar a coexistência dessas entidades, igualmente soberanas, igualmente capazes de exprimir uma vontade que as vincule $^{33}$, mas, necessariamente, nos limites impostos, de fato e logicamente, por esta coexistência de entidades iguais: "o direito da soberania permite todo ato que não atente contra outras soberanias "34. E é exatamente isso que emerge do julgado - e que a doutrina positivista se cuida de observar: "Ora, a limitação primordial que o direito internacional impõe ao Estado... ”: o direito internacional impõe limites ao Estado - à sua soberania, à sua independência, à sua atuação na esfera internacional ${ }^{35}$. E o próprio Anzilotti não defendeu coisa diversa quando, alguns anos mais tarde, considerou, em sua opinião individual anexada à opinião consultiva sobre o Regime Aduaneiro entre a Alemanha e a Áustria, que “ $a$ independência, assim entendida, é, de fato, a condição normal dos Estados segundo o direito internacional: ela também pode ser qualificada como soberania (suprema potestas) ou

132.

32 Opinião consultiva de 8 de julho de 1996, Rec. 1996, p.393.

${ }^{33}$ Cf. CPJI, julgado de 17 de agosto de 1923, Vapor Wimbledon, série A, no1, p.25.

34 Travers, op.cit. nota 20, p.415.

35 E estas limitações podem resultar de princípio suficientemente gerais - cf. CIJ, julgado de 18 de dezembro de 1951, Pêcheries, Rec.1951, p.252: “o único resultado é que faltando regras oferecedoras do caráter de precisão técnica afirmado pelo Governo do Reino Unido, a delimitação procedida pelo Governo norueguês em 1935 não está sujeita a certos princípios que permitam apreciar sua validade de acordo com o direito internacional".

Revista Publicum

Rio de Janeiro, v. 3, n. 1, 2017, p. 60-77

http://www.e-publicacoes.uerj.br/index.php/publicum

DOI: 10.12957/publicum.2017.30214 
soberania exterior, se por isso entendemos que o Estado não tem acima de si nenhuma outra autoridade, salvo aquela do direito internacional" 36 .

E é o imenso mérito da "teoria das competências", tal qual desenvolvida por Basdevant $^{37}$ na linha de suas alegações - justamente no caso Lotus -, de explicar esta situação: "no interior de seu círculo de competência, em seu domínio, o Estado pode invocar sua soberania; mas, para alargar sua competência, ele necessita um título reconhecido pelo direito internacional, ele tem que se apoiar sobre uma regra do direito internacional" 38 .

Assim concebida, a teoria das competências significa que o Estado, soberano como o é, fundamenta sua faculdade de agir no plano internacional no direito internacional e que, para agir, deve poder valer-se de um título - isto é, de uma habilitação resultante do direito internacional. Na doutrina tradicional, este título está ligado a cada um dos elementos constitutivos do Estado: trata-se da territorialidade, nacionalidade e do vínculo do serviço público. Contudo, para esclarecer o que seria este título, foi insuficiente: na falta de regra imperativa em sentido contrário, nada impede os Estados de se reconhecerem mutuamente competências além dos títulos de direito comum; poder-se-ia denominar tal fenômeno “convencionalidade". Mas, em qualquer caso, isto não seria assumir o lugar de alfa e de ômega como as interpretações estritamente positivistas do julgado Lotus querem fazer crer.

Em última análise, não são esses, mas aqueles que são criticáveis: apesar de uma formulação infeliz da origem das regras de direito internacional, onde não se pode razoavelmente sustentar que todas elas procedem da vontade do Estado - mesmo se a maior parte delas resultem-, a decisão Lotus não se encaixa nas teses dos autores positivistas (voluntaristas) - que, no entanto, a transformaram em um manifesto emblemático da posição que defendem:

- além das convenções, faz menção a "usos aceitos de forma geral como consagradores dos princípios de direito” (e aceitação geral não é unanimidade);

- aceita que essas são "estabelecidas visando regular a coexistência dessas comunidades independentes" (e a coexistência de soberanias implica em inevitáveis restrições);

${ }^{36} \mathrm{CPJI}$, de 5 de setembro de 1931, série A/B nํ41, p.57 - itálicos no texto.

37 V. em particular seu curso "Règles générales du droit de la paix", RCADI 1936-IV, vol. 58, pp.471692. V, também, Charles Rousseau, Droit internacional public, Tomo II, Les sujets, Sirey, Paris, 1974, pp. 68-93; Tomo III, Les compétences, Sirey, Paris, 1977, 635p.; “L'aménagement des compétences en droit international", RGDIP, 1930, pp. 420-460; Marcel Sibert, Traité de droit international public, le droit de la paix, Tomo I, pp. 647 et s.; Alfred Verdross, Völkerrecht, 5a ed., Springer Verlag, Wien, 1964, pp.240-242.

38 CPJI, série C, no 13/2, Réplica de Basdevant, 9 de agosto de 1927, pp. 150-151; v. de forma mais geral, pp. 149-151; v. ainda o discurso de Basdevant, 2 de agosto de 1927, pp. 38-39.

Revista Publicum

Rio de Janeiro, v. 3, n. 1, 2017, p. 60-77

http://www.e-publicacoes.uerj.br/index.php/publicum

DOI: 10.12957/publicum.2017.30214 
- admite expressamente que “o direito internacional impõe” limitações à soberania (que não pode, portanto, ter o caráter absoluto e ilimitado que a doutrina positivista gostaria de lhe conferir);

- limita a presunção de regularidade dos atos estatais ${ }^{39}$ ao território do Estado (e, assim fazendo, apenas reflete o princípio da "soberania territorial");

- e ela incide, ainda, no que nos parece ser uma falácia, uma vez que repousa sobre a ideia, agora abandonada, mas à época comumente aceita, que "em virtude do princípio da liberdade do mar, um navio é posto na mesma situação que o território do Estado"40.

No plano dos princípios, este postulado é, sem dúvida, tudo pelo que se pode criticar a posição majoritária da Corte (assim como a maior parte dos juízes dissidentes) ${ }^{41}$ - ainda que esta crítica não possa ser fundada numa perspectiva intertemporal. De resto, a decisão Lotus deve sua má-reputação mais à interpretação detestável que a doutrina a deu, do que a seus defeitos intrínsecos.

\section{Uma concepção ambígua da soberania justificada pela}

\section{sequência de posições diferentes e irreconciliáveis}

De resto, se o interpretamos como uma ode à soberania do Estado entendida dessa maneira absoluta, a decisão de 1927 aparece como relativamente isolada na jurisprudência da Corte mundial. Sem dúvida, é certo que, de tempos em tempos, ressurgem, com os "controversos fantasmas de Lotus"42, decisões onde o "odor" voluntarista é evidente ${ }^{43}$; contudo, tratamse de exceções limitadas incompatíveis com a abordagem cada vez mais aberta e "moderna" da soberania veiculada pela jurisprudência dominante, que, de um modo geral, se abstém de exaltar a soberania do Estado em detrimento da superioridade do direito internacional ${ }^{44}$.

${ }^{39}$ Sobre a distinção entre "presunção" e "princípio residual", v. O. Spiermann, op.cit. nota 11, pp.254255 e op.cit. nota 28 , pp.132-136.

40 Série A, no10, p.25.

${ }^{41}$ V. supra, notas 10 e 27.

42 M.-P. Lanfranchi et Th. Christakis, La licéité de l'emploi d'armes nucléaires devant la Cour internationale de Justice - Analyse et documents, Economica, Paris, p. 48.

43 O exemplo mais memorável (e mais lamentável) é, sem dúvidas, o fornecido pelo julgado de 14 de fevereiro de 2002 no caso do Mandat d'arrêt du 11 avril 2000, Rec. 2002, p. 3.

44 Para exemplos de decisões mais atentas aos limites impostos pela interdependência, v. (dentre outros) os julgados da CPJI no caso Vapor Wimbledon (julgamento de 17 de agosto de 1923, série A, nO 1) e da C.U. no caso do Détroit de Corfou (julgamento de 9 de abril de 1949, Rec. 1949, p. 4), ou as Opiniões Consultivas relativas à Reparação de danos causados em serviço às Nações Unidas (2 de abril 
De modo geral, a Corte não manifesta pela jurisprudência do Lotus a mesma paixão que a doutrina positivista. Ela pouco cita a decisão de 1927 e, quando o faz, visa preferencialmente o princípio jura novit curia ${ }^{45}$ ou as condições de formação do costume ${ }^{46}$, questões que, embora não desprovidas de vínculos com o problema aqui abordado, com ele se relacionam apenas indiretamente. E, certamente, é nas opiniões individuais ou dissidentes dos juízes que a concepção de soberania veiculada pelo julgamento da CPJI é invocado com maior frequência - e em sentidos diversos, cada Juiz lhe dando a interpretação que melhor se encaixa em suas concepções doutrinárias, mesmo ideológicas ${ }^{47}$. Esta diversidade confirma, se é necessário, o caráter maleável e incerto da posição que a Corte permanente adotou na decisão Lotus quanto à definição e às consequências do conceito de soberania.

A oposição entre essas análises é especialmente marcante nas opiniões pessoais anexas, de um lado, à Opinião Consultiva de 8 de julho de 1996 no caso da Licitude da ameaça ou do emprego de armas nucleares e, de outro, ao julgamento de 14 de fevereiro de 2002 no caso de Certos procedimentos penais em trâmite na França. Nos dois casos, elas refletem as mesmas incertezas e as mesmas divergências de opiniões quanto ao escopo da decisão Lotus.

Na opinião de 1996, o julgamento de 1927 é mencionado apenas em referência aos argumentos dos Estados e sobre a única interpretação da questão posta ${ }^{48}$, na qual pode-se ver uma alusão à ideia de que "tudo que não é proibido é permitido" - o que resulta frequentemente de uma visão caricatural da decisão Lotus ${ }^{49}$. Não é menos interessante notar que "[a] Corte observar que os Estados com armas nucleares que se manifestaram reconheceram ou não negaram que sua liberdade de agir está efetivamente limitada pelos princípios e regras de direito internacional e mais precisamente pelo direito humanitário"50,

de 1949, Rec. 1949, p. 174), às Reservas à Convenção sobre o Genocídio (28 de maio de 1951, Rec. 1951, p. 496) ou à Licitude da ameaça ou do uso de arma nuclear (Rec. 1996, p. 226).

${ }^{45}$ Cf. julgamento de 27 de junho de 1986, Atividades militares e paramilitares em Nicarágua e contra esta i (Nicarágua c. Estados Unidos da América, C.I.J. Recueil 1986, p. 24, par. 29.

46 Cf julgamento de 10 de fevereiro de 1929, Plataforma continental do mar do Norte (Alemanha/Dinamarca; Alemanha/Países Baixos), pp. 44-45, par.78.

47 Esta diversidade muito provavelmente seria ainda mais marcante se procedêssemos a um estudo dos posicionamentos doutrinários sobre os "princípios de Lotus"; o recorte do presente estudo, contudo, não o permite.

${ }^{48}$ Que foi mal formulado ("Ao Estado é lícito, de acordo com o direito internacional, recorrer à ameaça ou ao uso de armas nucleares em qualquer circunstância?”) - v. Ree. 1996, pp. 238-239, n²0-22.

${ }^{49}$ V. supra, p.[4].

50 Ree. 1996, p. 239, par. 22.

Revista Publicum

Rio de Janeiro, v. 3, n. 1, 2017, p. 60-77

http://www.e-publicacoes.uerj.br/index.php/publicum

DOI: 10.12957/publicum.2017.30214 
inclinando-se, aparentemente (mas prudentemente), em favor de uma interpretação "internacionalista" do Lotus.

As opiniões pessoais dos juízes são mais firmes e mais contrastantes porque, em divisão equilibrada, certas tentam se apropria das afirmações da Corte permanente como apoio de uma concepção extensiva da soberania, enquanto outros insistem em seu caráter obsoleto ou inaceitável.

O Presidente Bedjaoui, cuja voz preponderante permitiu alcançar uma solução (que se traduz em uma abstenção a responder por ser a questão posta "em uma circunstância extrema de legítima defesa na qual a própria sobrevivência de um Estado estaria em discussão" $\left.{ }^{\prime 51}\right)$, classifica-se claramente no último grupo:

\begin{abstract}
A jurisprudência do caso Lotus, que alguns não sentirão falta de ressuscitar, merece ser fortemente relativizada no contexto específico da questão objeto da presente opinião consultiva. O escopo desta decisão da Corte permanente seria deformado e sua importância exagerada se essa fosse isolada do contexto particular, por sua vez judicial e temporal, no qual interveio. A decisão em questão exprimia, sem dúvidas, o espírito do tempo, aquele de uma sociedade internacional ainda pouco institucionalizada e regida por um direito internacional de estrita coexistência, ele mesmo reflexo da vigência do princípio da soberania do Estado.

Vale a pena sublinhar que a fisionomia da sociedade internacional contemporânea é sensivelmente diferente. A despeito do avanço ainda limitado do 'supranacionalismo', não há como negar os progressos registrados no nível da institucionalização, ou ainda da integração e da 'globalização', da sociedade internacional. Estão como provas a multiplicação das organizações internacionais, a substituição progressiva do direito internacional clássico da coexistência por um direito internacional de cooperação, a emergência do conceito de 'comunidade internacional' e as tentativas, por vezes coroadas de sucesso, de subjetivação desta última ${ }^{52}$.
\end{abstract}

Neste mesmo espírito, o Juiz Weeramantry relembrou que, "[n]o decorrer do último século que se passou após o caso Lotus, o direito internacional e o direito relativo ao comportamento humanitário em tempos de guerra evidentemente evoluíram de modo considerável, adicionando novas restrições à soberania dos Estados às que existiam à época do caso em questão. (...). A Corte não pode, em 1996, endossar uma interpretação da decisão Lotus tão estreita que levaria o direito ao ponto onde se encontrava antes da cláusula Martens" ${ }^{\prime \prime 3}$.

\footnotetext{
51 Opinião consultiva de 8 de julho de 1996, Ree. 1996, p. 266, par. 105.E; v. também p. 263, par. 97.

52 Declaração do Presidente Bedjaoui, ibid., p.270, pars. 12 e 13.

53 Opinião dissidente do Juiz Weeramentry, ibid., pars. 12 e 13.
}

Revista Publicum

Rio de Janeiro, v. 3, n. 1, 2017, p. 60-77

http://www.e-publicacoes.uerj.br/index.php/publicum

DOI: 10.12957/publicum.2017.30214 
Isto confirma a fórmula impressionante de um comentador: "graças aos 'princípios cardeais $^{\prime 54}$ (...), o direito humanitário é incontestavelmente um 'direito anti-Lotus"'155, e foi assim que o próprio Bedjaoui confirmou quando, curiosamente, declarou - por ocasião de um colóquio universitário - que "os famosos parágrafos que nos dividiram são, se observarmos, apenas uma porta em trompe-l'oeil ${ }^{56}$ destinada a nos enganar. Mas essa porta em trompe-l'oeil foi desenhada em uma muralha intransponível, uma vez que é composta particularmente por normas imperativas de direito internacional geral" ${ }^{25}$. Isso equivale a enterrar o Lotus (ao menos se aceitarmos a ideia de que a decisão de 1927 resulta de uma "abordagem decididamente positivista" ${ }^{58}$ )

Mas tal "muralha" não parece ser suficientemente "intransponível" ao Juiz Shahabuddeen que, em sua opinião dissidente, ressalta, não sem rigor ou razão, que "quando se analisa esta conclusão da opinião formulada no caso Lotus, pode-se ser levado a concluir que, de acordo com a Corte, existe uma possibilidade de o emprego de armas nucleares ser lícito em certas circunstâncias e que cabe aos Estados decidir se esta possibilidade existe em dadas circunstâncias" ${ }^{\prime 59}$. Entretanto, colocando-se perante quatro interpretações possíveis (e diferentes) da decisão de 1927, o eminente Juiz considera que, em qualquer caso, estas não permitem dar uma resposta positiva ou mesmo duvidosa à questão formulada ${ }^{60}$ :

- admitindo-se que "um Estado tem o direito de fazer tudo que não seja proibido", o uso da arma nuclear resultaria inevitavelmente em violação aos direitos dos Estados neutros ${ }^{61}$;

- toda "ação que reduziria à nada a civilização e a humanidade" é incompatível com a Carta ${ }^{62}$;

\footnotetext{
${ }^{54}$ V.Rec. 1996,p.257, par. 78.

55 Vincent Coussirat-Coustère, "La licéité des armes nucléaires en question" in S.F.D.I., Journée d'études, Le droit international des armes nucléaires, Pedone, Paris, p. 101.

${ }^{56} \mathrm{NT}$ : técnica de pintura destinada a criar ilusão tridimensional.

57 Debates, Vincent Coussirat-Coustère, "La licéité des armes nucléaires en question" in S.F.D.I., Journée d'études, Le droit international des armes nucléaires, Pedone, Paris, p.103.

58 Declaração do Presidente Bedjaoui, Rec. 1996, p. 270, par. 13.

59 Ibid., p.376; v. também p.426: “O que a Corte entendeu deixar no domínio do possível ganha uma consistência mais firme à luz do caso Lotus, tal qual é comumente interpretado. Enquanto a Corte diz não poder se manifestar de forma definitiva, ela diz que não pode se manifestar definitivamente sobre o ponto de saber se existe ou não uma regra proibitiva". Em sua declaração, o Presidente Bedjaoui tenta desarmar a objeção (ibid., p. 271, par. 14, e p.273, par. 22).

60 lbid., pp. 391-397.

61 lbid., p.391.

62 Ibid.
}

Revista Publicum

Rio de Janeiro, v. 3, n. 1, 2017, p. 60-77

http://www.e-publicacoes.uerj.br/index.php/publicum

DOI: $10.12957 /$ publicum.2017.30214 
- a decisão Lotus reconhece que "a coexistência de ... comunidades independentes" constitui o "quadro estrutural objetivo no qual a soberania deve necessariamente existir"63; e,

- a questão que os juízes de 1927 deviam resolver não possuir relação, tampouco medida comum, com a que lhes foi posta em 1996 e

[a]s noções de soberania e de independência que a Corte levou em consideração ao atuar no caso Lotus não se encaixam em um contexto em que é possível prever a capacidade de um Estado sozinho destruir e aniquilar todos os outros Estados. A Corte tinha que examinar um caso de colisão em mar e a questão da competência penal dos Estados a este respeito. Não se pode afirmar que havia algo no caso suficiente para perturbar os espíritos. Se a Corte pudesse ter imaginado a possibilidade de uma minoria de Estados beligerantes destruir o planeta, ela provavelmente teria melhor especificado a posição que adotou... ${ }^{64}$

Não se pode melhor dizer que a jurisprudência Lotus, mesmo aceintando o sentido absoluto e discutível que os autores positivistas querem lhe conferir, não possui um valor geral e que o princípio de acordo com o qual "tudo que não é proibido é permitido", aceitável quando se trata de exercer a competência penal conforme o princípio da territorialidade, não pode ser brandido em contextos completamente diferentes.

Eis que, ao menos aparência, contrasta de forma impressionante a posição do Juiz Guillaume, que afirma, afastando-se da interpretação estritamente positivista do Lotus à qual se atém rigorosamente, independente das evoluções que o direito internacional conheceu desde então:

O direito internacional repousa, de fato, sobre o princípio da soberania dos Estados e se origina consequentemente do consentimento desses. Em outros termos, como afirmou excelentemente a Corte permanente, 'o direito internacional rege as relações entre os Estados independentes. As regras de direito ligando os Estados se originam, portanto, da vontade desses' (Lotus, julgado número 9, 1927, CPJI, série $A, n$ o 10, p.18.).

E acrescentou, certamente para melhor "pregar o caixão", mas, na verdade, melhor nuançando o aspecto categórico de sua afirmação:

A própria Corte teve oportunidade de se debruçar de diversas formas sobre as consequências deste princípio no caso opondo a Nicarágua e os Estados Unidos da América. Ela afirmou que o "princípio da soberania dos Estados permite a cada um desses de se decidir livremente" pelo que é "da escolha do

\author{
63 Ibid., p.392; v. supra, pp. [5-6]. \\ 64 Ibid., p.395 \\ Revista Publicum \\ Rio de Janeiro, v. 3, n. 1, 2017, p. 60-77 \\ http://www.e-publicacoes.uerj.br/index.php/publicum \\ DOI: 10.12957/publicum.2017.30214
}


sistema político, econômico, social e cultural e da formulação das relações exteriores" (Atividades militares e paramilitares na Nicarágua e contra esta [Nicarágua c. Estados Unidos da América], CIJ Récueil 1986, p. 108). Ela precisou sobretudo "que não há, no direito internacional, regras, além daquelas que o Estado interessado possa aceitar, por tratado ou outra forma, que imponham limitação ao nível armamentista de um Estado soberano, este princípio sendo válido para todos os Estados sem distinção" (ibid., p. 135).

Estas precisões devem, sem dúvida, serem nuançadas à luz dos princípios "intransigíveis" do direito internacional contemporâneo (que excluem a licitude de regimes sanguinários não respeitadores dos princípios protetores de direitos fundamentais da pessoa humana). Mas, em qualquer estado de causa, não fazem nada além do que confirmar os direitos amplamente entendidos de todo Estado de se comportar como quiser em seu território este que constitui o aspecto menos discutível do julgamento de 1927, sem justificar uma concepção estritamente positivista do direito internacional.

A verdade é que, mesmo se suas certezas sejam desigualmente rígidas e suas conclusões diferentes, todos os Juízes que, no caso da Licitude, se posicionaram em relação à jurisprudência de Lotus, a interpretaram afinal em uma perspectiva "territorialista": eles admitem que "em sua casa, cada um é rei", mas hesitam em explicitar consequências mais gerais.

A análise dos posicionamentos adotados por diversos Juízes nas opiniões pessoais que apresentaram ao julgado da Corte de 14 de fevereiro de 2002 no caso Yerodia conduz a constatações comparáveis.

É, sem dúvida, neste caso que o problema da validade permanente dos “princípios Lotus" foi posta com maior acuidade: vindos de Sirius, os fatos que resultaram nos dois casos apresentam uma certa similaridade e apresentam problemas jurídicos vizinhos porque, em ambos, trata-se de determinar os limites à competência de um Estado para julgar os crimes cometidos por um estrangeiro. A Corte tendo decidido, por uma razão muito discutível, não se pronunciar sobre o outro fundamento levantado pela Bélgica (e afastar as imunidades que beneficiariam a pessoa em questão) ${ }^{65}$, não abordou a questão nesses termos. Mas diversas opiniões pessoais foram emitidas e seus autores teceram adequadamente comparações com o julgado de 1927 - que ambas as Partes haviam invocado em argumentos em favor de suas teses ${ }^{66}$.

\footnotetext{
65 Julgado de 14 de fevereiro de 2002, Mandat d'arrêt de 14 de fevereiro de 2002, Rec. 2002, p.19., par.45.

${ }^{66}$ V. notavelmente memoriais da Bélgica, pp. 89-90, pars. 3.3.29-3.3.32; CR 200116, 16 de outubro de 2001, pp. 3-34 (Chemillier-Gendreau); CR 200119, 18 de outubro de 2001, pp. 10-11, par. 10 (6) (E. David). 
Os Juízes que tomaram partido sobre este ponto reconheceram a pertinência do Lotus, seja para afastá-lo, enfatizando seu caráter defasado, seja para fazê-lo prevalecer.

As opiniões individuais dos Juízes Guillaume, Ranjeva ou Rezek são sobretudo neste último sentido: eles ressaltam a concepção estritamente territorial, mas, neste caso, extensivo, da soberania que traduz o julgado de 1927. Na declaração que anexou à decisão, o Presidente Guillaume admite que "o direito internacional clássico não impede que o Estado possa, em certos casos, exercer sua competência jurisdicional sobre infrações cometidas no estrangeiro. Mas, como havia (...) decidido a Corte permanente no caso Lotus, tal exercício não é ilimitado" ${ }^{\prime 67}$. São estes, portanto, os limites à competência extraterritorial que chamam a atenção do ilustre Juiz ${ }^{68}$. Por sua vez, o Juiz Ranjeva reconhece que "podese analisar a evolução das ideias e das condições políticas no mundo contemporâneo como favoráveis a uma atenuação da concepção territorialista da competência e a uma emergência de uma abordagem mais funcionalista no sentido de um serviço em benefício das finalidades superiores comuns"; mas adiciona que "o caráter territorial da base do título de competência ainda resta como um dos valores seguros, o núcleo duro do direito internacional positivo contemporâneo" ${ }^{\prime \prime 9}$.

A opinião individual conjunta que os Juízes Higgins, Kooijmans e Buergenthal apresentaram ao julgado enseja a análise mais distante e manifesta uma certa desconfiança em relação à abordagem da Corte permanente. Após ter citado "a célebre observação incidente" dessa ${ }^{70}$, adicionam:

\begin{abstract}
A aplicação desta decisão célebre seria manifestamente perigosa em certos domínios do direito internacional. (Vide, sobre este ponto, a opinião dissidente de Shahabuddeen no caso da Licitude da ameaça ou do uso de armas nucleares, CIJ Récueil 1996, p.394-396.) Ela resta possível, contudo, no contexto da competência em relação aos crimes internacionais.

Dito isso, esta observação incidente corresponde ao apogeu do laissez-faire nas relações internacionais e à uma época que foi sensivelmente superada por outras tendências, especialmente a tomada de consciência da necessidade de agir contra as atrocidades. "Esta concepção vertical do poder de agir é sensivelmente diferente do sistema horizontal de direito internacional vislumbrado no caso do Lotus"17.
\end{abstract}

67 Rec. 2002, p. 37, nO 4; v. também, p. 42, no 13.

68 V. também a opinião individual do Juiz Rezek, que se refere implicitamente à teoria das competências (ibid., p.92, pars. 5-6). Na petição apresentada em 11 de abril de 2003 sobre Certos procedimentos penais adotados na França, o Congo evoca a opinião de Guillaume (p.4).

${ }^{69}$ Declaração, ibid., pp. 57-58, $n^{\circ} 9$.

70 V. supra p. [4] (série A, $n^{\circ} 10$, pp. 18-19).

${ }^{71}$ Rec. 2002, p. 78, pars. 50-51; no mesmo sentido, v. as observações do Juiz Alvarez em suas opiniões individuais no caso das Pêcheries sobre o pretenso "direito dos Estados a fazer tudo que não seja expressamente proibido pelo direito internacional" (julgado de 18 de dezembro de 1951, Rec. 1951,

Revista Publicum

Rio de Janeiro, v. 3, n. 1, 2017, p. 60-77

http://www.e-publicacoes.uerj.br/index.php/publicum

DOI: 10.12957/publicum.2017.30214 
Por sua vez, enfim, Van den Wyngaert, Juíza ad hoc da Bélgica, examina atentamente a questão de saber se "a competência universal pelos crimes de guerra e crimes contra a humanidade é compatível com o critério de Lotus"72, e conclui afirmativamente, após ter recordado que, conforme a formulação do julgado de $1927^{73}$, "a limitação primordial que o direito internacional impõe [aos Estados]" é que estes não se beneficiem de nenhuma competência executiva sobre o território de outro Estado na falta de autorização desse ${ }^{74}$.

De modo significativo, cada um dá ênfase aos aspectos da jurisprudência Lotus que correspondem à sua "sensibilidade" doutrinária ou ideológica. Mas, isolando certos elementos em detrimento dos outros, todos subestimam suas complexidades e nuances.

A decisão de 1927 foi descrita como "uma mina de material valioso sobre a matéria da jurisdição $o^{\prime 75}$. Isso é certamente verdadeiro - desde que não se parta da ideia preconcebida e falsa que ela responde de modo geral e definitivo as questões fundamentais, que teve o mérito de levantar, mas que aplica exclusivamente aos fatos, deveras inofensivos, do caso.

$\mathrm{Na}$ verdade, não há "princípios Lotus", mas um conjunto de considerações notavelmente vastas e diversas, as quais a Corte permanente aplicou de modo particular no contexto específico no qual emitiu sua decisão:

- o direito internacional rege as relações entre Estados independentes? Sim mas não somente entre esses; e a extensão de sua aplicação a outros sujeitos, marginal e difícil de identificar em 1927, desde então se ampliou consideravelmente;

- as regras de direito internacional se originam da vontade dos Estados? Sim, na maior parte dos casos, porque os tratados, emanados dessa, são a origem da maior parte de tais regras; mas a observação, objetiva e honesta, da realidade jurídica internacional mostra que a vontade estatal não basta para explicar a formação de todas as normas jurídicas internacionais (e não apenas o fato de existirem raras regras de jus cogens);

- as limitações à soberania não são presumíveis? Ainda sim, mas a soberania é, na ordem internacional, um conceito "limitado" por essência: a liberdade de agir de cada Estado é "limitada" por aquela, igual, de todos os outros;

p.152), e dissidente no caso da Anglo-Iranian Oil Co. sobre a evolução do domínio reservado (julgado de 22 de julho de 1952, pp. 127-128).

72 bid., pp. 167-175, pars. 48-62.

${ }^{73}$ V. supra, p. [2] (série $A, n^{\circ} 10$, p. 18).

${ }^{74}$ Rec. 2002, p. $158, n^{\circ} 49$.

75 Oppenheim 's International Law, 5th ed. by Hersch Lauterpacht, vol. I, Londres, Longman, 1935, p.270.

Revista Publicum

Rio de Janeiro, v. 3, n. 1, 2017, p. 60-77

http://www.e-publicacoes.uerj.br/index.php/publicum

DOI: 10.12957/publicum.2017.30214 
- tudo que não é proibido é permitido? Pode ser que sim - mas isso somente é verdade para as ações conduzidas pelo Estado em seu próprio território, e corresponde ao que atualmente chamamos de "soberania territorial', que engloba as competências particularmente entendidas que um Estado exerce em razão de um título territorial, excluídas aquelas fundadas em outro título de competência;

- estas, aliás, não são ilimitadas, pois, em todas as suas atividades, o Estado está sujeito às regras do direito internacional: embora o paralelo não possa ser levado muito longe, este é o equivalente internacional da noção de "Estado de Direito", tal como ela se impõe, não sem dificuldade, na ordem interna.

O caminho ainda é longo para essa possa prevalecer com toda força e todas suas consequências na ordem internacional. Mas não é certamente um vínculo fanático com uma interpretação rigidamente positivista (e de modo algum inevitável) com jurisprudência Lotus que facilitará esta conquista. 